\title{
Article \\ Effects of Injection Rate Shape on Performance and Emissions of a Diesel Engine Fuelled by Diesel and Biodiesel B20
}

\author{
Andrei Laurentiu Niculae ${ }^{1, *}\left(\mathbb{0}\right.$, Radu Chiriac $^{1,2}$ and Alexandru Racovitza ${ }^{1}$ \\ 1 Faculty of Mechanical Engineering and Mechatronics, University Politehnica of Bucharest, \\ Splaiul Independenței 313, 060042 Bucharest, Romania; raduchiriac2001@yahoo.com (R.C.); \\ racovitzaalexandru@gmail.com (A.R.) \\ 2 EA7341 CMGPCE of Conservatoire National des Arts et Metiers, 292 Rue Saint-Martin, 75003 Paris, France \\ * Correspondence: andrei.niculae@upb.ro
}

Citation: Niculae, A.L.; Chiriac, R.; Racovitza, A. Effects of Injection Rate Shape on Performance and Emissions of a Diesel Engine Fuelled by Diesel and Biodiesel B20. Appl. Sci. 2022, 12, 1333. https://doi.org/10.3390/ app12031333

Academic Editor: Dmitrii

O. Glushkov

Received: 28 December 2021

Accepted: 24 January 2022

Published: 26 January 2022

Publisher's Note: MDPI stays neutral with regard to jurisdictional claims in published maps and institutional affiliations.

Copyright: (c) 2022 by the authors. Licensee MDPI, Basel, Switzerland. This article is an open access article distributed under the terms and conditions of the Creative Commons Attribution (CC BY) license (https:// creativecommons.org/licenses/by/ $4.0 /)$.

\begin{abstract}
The combustion process in diesel engines is controlled by the injection rate shape. The stricter emission regulations requiring simultaneous reduction of nitrogen oxides and particulate matter imposes intense research and development activity for achieving clean and robust combustion. This work describes the experimental investigation made for calibration of an engine model and the numerical investigation performed to assess the influences of different injection rate shapes on performances of a diesel engine fuelled with diesel and rapeseed biodiesel B20. The engine model was developed with the AVL-BOOST code using the AVL-MCC combustion mode. The model was calibrated for the reference Top-Hat injection rate shape using experimental data registered for maximum brake torque and maximum brake power speed conditions. Other injection rate shapes such as triangular, trapezoidal, and boot having the same area, start, and duration of injection were investigated in terms of combustion characteristics, performance, and pollutant emissions. The link existing between the injection characteristics and the $\mathrm{NO}_{\mathrm{x}}$ and Soot emissions highlights that, for the optimal rate of injection shape, a simultaneous reduction of $\mathrm{NO}_{\mathrm{x}}$ and Soot by $11 \%$, respectively $4 \%$ for maximum brake torque and by $22 \%$, respectively $7 \%$ for maximum brake power, can be obtained using biodiesel B20.
\end{abstract}

Keywords: diesel engine; injection rate-shaping; combustion characteristics; emissions; biodiesel B20

\section{Introduction}

Diesel engines are usually used in many applications for transport, industry, power generation, agricultural and military sectors. Clean combustion achieved by adaptive control of engine operation using the injection rate-shaping has received nowadays major significance to ensure increased efficiency and low levels of emissions. By adopting a modern combustion system design accompanied with an advanced fuel injection system, high power and torque densities together with low fuel consumption and emissions can be achieved [1].

Renewable and sustainable alternative fuels such as biofuels can be a solution to the increased demand for fuels and the depletion of oil resources. Also, the association of advanced fuel formulations with highly efficient engine combustion architectures can be a suitable solution for the challenges related to efficiency and emission targets in the short-medium term [2]. The transport sector is the primary consumer of petroleum-derived fuels. Diesel engines are constructed to run on diesel fuel and the alternative fuel should have similar characteristics. Although many studies have been carried out on alternative fuels for diesel engines, the main obstacle which must be overpassed is the elevated cost of these fuels and the difficulties associated with engine changes enabling the operation with these fuels. Some studies have shown that by fuelling the engine with blends of crude palm oil or biodiesel with diesel, a simultaneous reduction of $\mathrm{HC}, \mathrm{NO}_{\mathrm{x}}$ and Soot emissions 
is possible [3,4]. In this sense, biodiesel is actually considered the only alternative fuel that can be used without or with small modifications to the diesel engine having a significant effect on emissions mitigation [5].

In the last decades, several experimental and numerical studies have been developed aimed to examine the effect of various shapes of the rate of injection on diesel engine operation. Most of them showed that the adoption of single injection strategies with modified shapes of the rate of injection can be a very efficient method for decreasing $\mathrm{NO}_{\mathrm{x}}$ emissions at some loading conditions [6]. Also, the combustion-generated noise can be reduced if there is a lower initial injected fuel mass, thus slowing down the early rapid rise of the heat release and peak pressure rise rate [7]. In other studies, the adoption of different shapes of the rate of injection has been achieved considering split injection strategies [8-10]. Changing the main injection shape has an important effect on the air-fuel mixing process, ignition delay and pollutant emissions. According to [8], it is likely to attain low $\mathrm{NO}_{\mathrm{x}}$ and Soot emissions at the same time by using the proper rate shape.

The experimental study conducted by Macian et al. [11] shows that boot and ramp rate of injection profiles have an important influence over the premixed combustion phase and the ignition location without changing the injection pressure or the final fuel mass flow rate. According to [12], $\mathrm{NO}_{\mathrm{x}}$ forms in zones that are close to the stoichiometric and Soot forms in zones with equivalence ratios between two and four. Therefore, the variation of fuel delivery through the change of injection rate shape can be a valuable method of emission control. Desantes et al. $[13,14]$ observed important reductions in $\mathrm{NO}_{\mathbf{x}}$ emissions with increasing boot length or decreasing boot pressure. Less efficient mixing conditions are provided when the boot shape length is increased, which amplifies Soot emissions drastically. An improved mixing can be obtained if the boot pressure is increased, which provides rapid burning rates, with higher $\mathrm{NO}_{\mathrm{x}}$ and lower Soot emissions.

Using computational fluid dynamics (CFD) software, Shrestha et al. [15] observed notable differences in the ignition delays among the considered rate shapes with the same start and duration of injection. Using a right-angled triangle shape with greater pressure at the end of the injection event leads to the lowest $\mathrm{NO}_{\mathrm{x}}$, but the highest Soot emissions. If the peak pressure is provided at the start of the injection event low values of Soot emissions are reported. Hountalas et al. [16] examined the opportunity of applying a phenomenological multi-zone model modified accordingly to consider various injection rates. Considering the entire engine behaviour, the boot rate with bigger pressure at the end of the injection process was the best shape, while the constant rate was the least effective. Shuai et al. [17] used seven rate shapes, the start of injection for each of them being tuned so that all determined the same trigger point of the main heat release. The rectangular shape and the boot-type shape delivering the peak velocity at the end of the injection can reduce Soot, $\mathrm{HC}$, and CO emissions in comparison to the trapezoidal, triangular and respectively to the boot-type shapes, which deliver the peak injection velocity at the start of the injection event.

According to Tay et al. [18-20], the triangular shapes of injection present bigger incylinder pressure rise rates relative to the ramp injection profiles. The duration of the combustion process decreases when the initial injection rate is higher and increases when a larger amount of fuel is introduced in the last part of the injection process. The ignition delay period lengthens when initial injection velocities are decreasing. If boot shapes with higher pressures at the end of the injection event are used, the combustion phasing occurs differently, and the $\mathrm{NO}$ emissions are usually decreasing in comparison with the conventional rectangular injection rate. When the boot injection rate is lower, greater Soot particles are formed.

Zhixia He et al. [21] performed a numerical study based on the adoption of four injection rate shapes (saddle, rectangle, triangle, and hump) considering constant injected fuel quantity and injection period. The start of the injection event for hump and saddle rates appears before the start of the injection for the triangle rate. Higher $\mathrm{NO}_{\mathrm{x}}$ emissions were formed for these shapes as a result of the greater high-temperature area and this is the consequence of bigger initial injection pressure promoting improved atomization and 
reduced ignition delay. The Soot emissions for hump rate were improved compared to the other shapes because of the higher pressure in the later injection period that improves the mixing of fuel and air.

Five shapes of the rate of injection were studied in [22]. The highest peak combustion temperature was reached for the triangle shape (highest $\mathrm{NO}_{\mathrm{x}}$ emissions) as a result of the greater rate at a certain injection moment. The rectangle shape represented the optimum for Soot and $\mathrm{NO}_{\mathrm{x}}$ emissions. The slope shape offered a moderate level of $\mathrm{HC}$ and the minimum $\mathrm{CO}$ emissions. As a result of delayed heat release, the wedge shape led to a low level of $\mathrm{NO}_{\mathrm{x}}$, but a high level of Soot emissions. The trapezoid shape offered the lowest Soot and a moderate level of $\mathrm{NO}_{\mathrm{x}}$ emissions.

Mohan et al. [23] investigated different boot injection profiles by varying the pressure and length of the shape for a biodiesel-fuelled engine. Simulation results revealed that $\mathrm{NO}_{\mathrm{x}}$ emissions were reduced when a lower fuel quantity has been introduced in the initial stage of injection and thus a lower fuel injection velocity resulted. The long boot length and high boot pressure shapes can be the solution to achieve the compromise between $\mathrm{NO}_{\mathrm{x}}$ and Soot.

There are many research papers dedicated to studying the consequences of changing the injection rate shape on diesel engine combustion process and emissions formation using different CFD software. Although CFD tools are highly efficient, they consume a lot of time and computing resources. In this study, the AVL-MCC zero-dimensional combustion model which is included in the AVL BOOST software, dedicated mainly to the internal combustion engine operation by simulation, was the key part of the research activity. This zero-dimensional approach offers accurate results in the computation of the combustion characteristics, performance, efficiency, and pollutant emissions of a tractor diesel engine fuelled with B20 (20\% biodiesel from rapeseed oil and $80 \%$ diesel) and diesel using various rate profiles of the injection pulse. The model was calibrated for two engine operating conditions (maximum brake torque and maximum brake power) using the experimental data registered on the engine test bench. There is a lack of information in the literature about the effects of injection rate shaping when fuelling the diesel engine with biodiesel B20, a perspective fuel in the current context in which solutions to reduce $\mathrm{CO}_{2}$ emissions are required. Thus, the novelty of this study consists in the presentation of original results, which fill the existing gap in the literature concerning the influence of the rate of injection shape on performance and emissions of a diesel engine fuelled with biodiesel B20. This study evaluates which pollutant emissions, like nitrogen oxides $\left(\mathrm{NO}_{\mathrm{x}}\right)$ and Soot, can be reduced without significant power losses or considerable growths in brake-specific fuel consumption when the shape of the injection rate is changed. Highlighting the linear correlation existing between the amount of fuel injected during the initial combustion phase and the values of $\mathrm{NO}_{\mathrm{x}}$ and Soot is another important element of originality. The study intentions were to determine an optimal ROI shape when the classical diesel fuel is replaced by B20 using the analysis of combustion characteristics. The results are presented comparatively for both fuels considering two meaningful operating conditions of an agricultural tractor diesel engine: the maximum brake torque (R1) and the maximum brake power (R2). The engine operation with the optimum injection rate shape (Boot 2) showed that it is possible to obtain a simultaneous reduction of $\mathrm{NO}_{x}$ and Soot emissions by $17 \%$, respectively $9 \%$ for diesel fuel on R1 test condition and by $28 \%$, respectively $12 \%$ on R 2 test condition. The replacement of diesel fuel by biodiesel $\mathrm{B} 20$ generates similar reductions of $\mathrm{NO}_{\mathrm{x}}$ and Soot by $11 \%$, respectively $4 \%$ on R 1 test condition and by $22 \%$, respectively $7 \%$ on R 2 test condition.

\section{Experimental Details}

The investigation was performed on a naturally aspirated, four-stroke tractor diesel engine UTB 2404055, which develops $48 \mathrm{~kW}$ at $2400 \mathrm{rpm}$ constant speed. The engine specifications are presented in Table 1. 
Table 1. Technical specifications of the diesel engine.

\begin{tabular}{ccccccccc}
\hline $\begin{array}{c}\text { Maximum } \\
\text { Brake Power }\end{array}$ & $\begin{array}{c}\text { Maximum } \\
\text { Brake Torque }\end{array}$ & $\begin{array}{c}\text { Cylinder } \\
\text { Bore }\end{array}$ & $\begin{array}{c}\text { Piston } \\
\text { Stroke }\end{array}$ & CR & $\begin{array}{c}\text { No. of } \\
\text { Cylinders }\end{array}$ & $\begin{array}{c}\text { Displacement } \\
\text { (L) }\end{array}$ & $\begin{array}{c}\text { Fuelling } \\
\text { System }\end{array}$ & $\begin{array}{c}\text { Injection } \\
\text { System }\end{array}$ \\
\hline $\begin{array}{c}48 \mathrm{~kW} / \\
2400 \mathrm{rpm}\end{array}$ & $\begin{array}{c}224 \mathrm{Nm} / \\
1400 \mathrm{rpm}\end{array}$ & $102 \mathrm{~mm}$ & $115 \mathrm{~mm}$ & 17.5 & 4 & 3.76 & $\begin{array}{c}\text { Direct } \\
\text { injection }\end{array}$ & Delphi \\
\hline
\end{tabular}

CR: Compression Ratio.

The engine was installed in a test cell provided with the corresponding instrumentation for experimental investigation (Figure 1). The test bench was equipped with an AVL Alpha 160 eddy current dynamometer which accurately measures the engine instant torque and speed. The unit under test is monitored and controlled by the AVL EMCON 400. The SCHLUMBERGER Fluxi 2000/TZ volumetric flow meter was used to measure the engine air consumption. The AVL Dynamic Fuel Meter 733S and AVL Fuel Temperature Controller 753C were used to measure the engine fuel consumption. The HORIBA Mexa $7170 \mathrm{D}$ gas analyser was used to measure the exhaust emissions of $\mathrm{CO}_{2}, \mathrm{CO}, \mathrm{NO}_{\mathrm{x}}$ and THC and to calculate the relative air-fuel ratio, while the AVL 415S measured the exhaust smoke expressed as Filter Smoke Number (FSN). The temperature and pressure of the exhaust gases, cooling water, intake air, oil as well as the atmospheric temperature and pressure were measured with appropriate devices through the signal conditioning system AVL FEM BOX and recorded by the AVL Puma Open v1.4 equipment. The data acquisition system for pressure diagrams consisted of an AVL 365C crank angle encoder and two AVL GM12D piezoelectric pressure transducers which were mounted in different cylinders and connected to the AVL 3066A02 charge amplifiers.

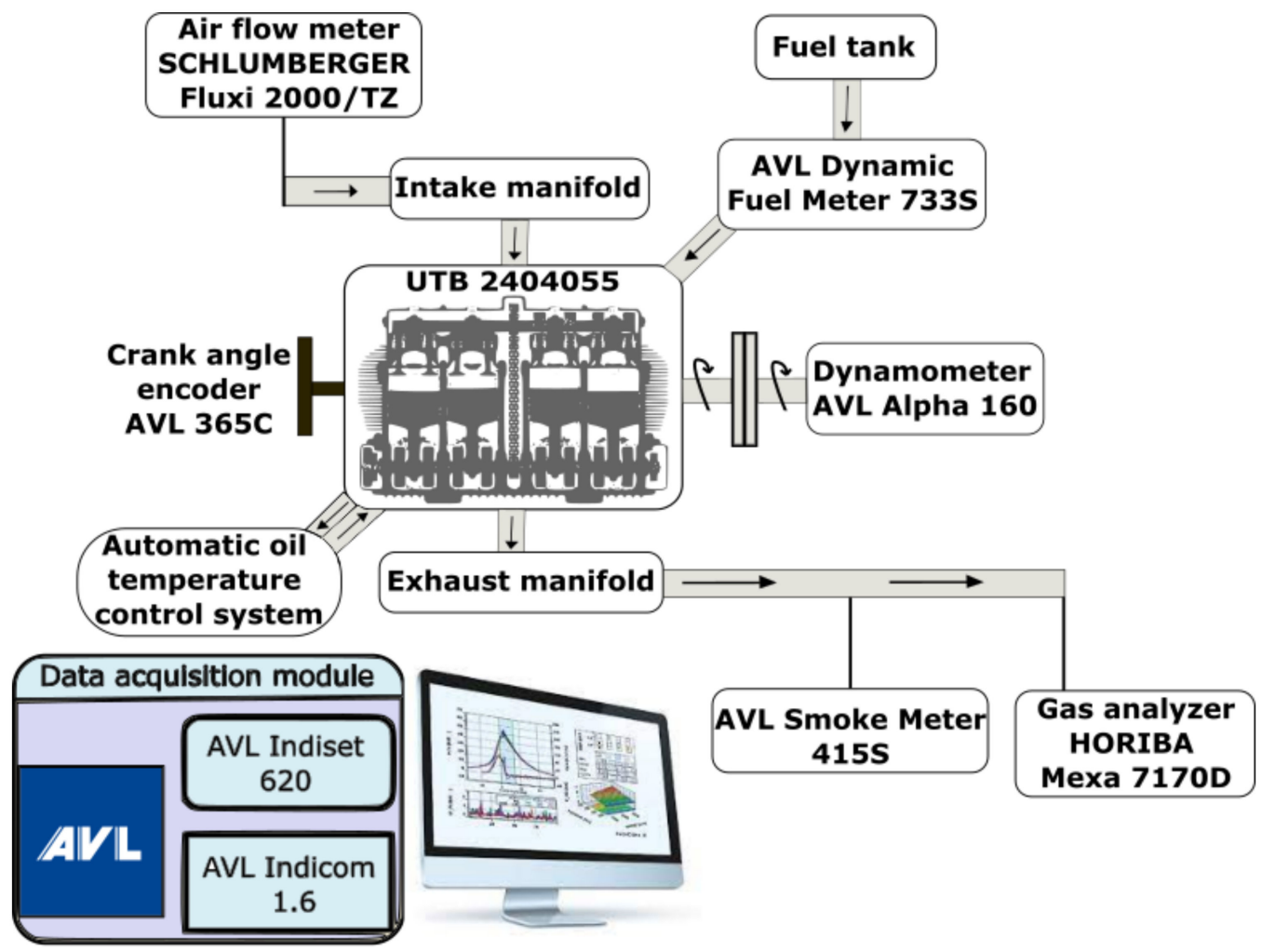

Figure 1. Engine test bench layout. 
The injector needle lift was recorded for one cylinder using a proximity sensor incorporated in a Perkins-Lucas injector. The AVL 3066A01 charge amplifier and AVL QL21D transducer equipped the high-pressure line of this injector. The fuel pressure measurement system at the injection pump consisted of an AVL 3009 A03 charge amplifier and an AVL 31 DP pressure transducer. An AVL IndiSet 620 data acquisition module recorded high-speed variation parameters using the AVL Indicom 1.6 software.

In this work, the experimental data were collected for engine maximum brake torqueR1 (full load, $1400 \mathrm{rpm}$ ) and maximum brake power-R2 (full load, $2400 \mathrm{rpm}$ ) conditions when fuelling was successively made with diesel fuel and biodiesel B20. For every operating point, at least 3 tests were performed, each of them consisting in the registration of 200 consecutive cycles recorded cycle by cycle, an average cycle and statistical data. The relative deviations of the in-cylinder pressure variation comparative to the mean values were below $3 \%$. The oil temperature stayed within $90 \pm 5{ }^{\circ} \mathrm{C}$ throughout the experiments. This was done using a heat exchanger equipped with two OMRON E5CN temperature controllers and electrovalves. The temperature of the engine cooling water was maintained between 70 and $75^{\circ} \mathrm{C}$. The experimental data which were averaged have been considered as the basis for the calibration of the simulation model.

Table 2 shows the measuring accuracy values for the main equipment used in this study.

Table 2. Measuring accuracy for each device of the main equipment used.

\begin{tabular}{cccccc}
\hline $\begin{array}{c}\text { AVL Alpha 160 } \\
\text { Dynamometer }\end{array}$ & $\begin{array}{c}\text { AVL 365C } \\
\text { Crank Angle } \\
\text { Encoder }\end{array}$ & $\begin{array}{c}\text { AVL 733S } \\
\text { Dynamic Fuel } \\
\text { Meter }\end{array}$ & $\begin{array}{c}\text { Fluxi 2000/TZ } \\
\text { Volumetric Flow } \\
\text { Meter }\end{array}$ & $\begin{array}{c}\text { Horiba Mexa } \\
\text { 7170D Gas } \\
\text { Analyzer }\end{array}$ & AVL 415S Smoke Meter \\
\hline $0.2 \% \mathrm{FS}$ & $0.5 \mathrm{deg}$ CA & $0.12 \% \mathrm{MV}$ & $0.23 \% \mathrm{MV}$ & within $\pm 0.5 \% \mathrm{MV}$ & $\leq \pm(0.005 \mathrm{FSN}+3 \% \mathrm{MV})$ \\
\hline
\end{tabular}

FS: Full scale; MV: Measured value; FSN: Filter smoke number.

It is well known that carbon dioxide $\left(\mathrm{CO}_{2}\right)$ is one of the harmful emissions of piston engines with a massive influence on the greenhouse effect, which induces the global warming phenomenon. To combat this undesirable phenomenon, continuously reducing carbon dioxide emissions must be promoted. One way to achieve this important goal is by using biofuels. Currently, commercial diesel fuel in the European Union has a content of $7 \% v / v$ biodiesel (B7). The slow increase in the biofuel percentage allows the technological development of motor vehicles, the aim being to use high percentages of biofuel in the future to further reduce $\mathrm{CO}_{2}$ emissions. For this reason, biodiesel B20 was considered important in this study, representing a potentially viable solution for the next future as it has only $20 \%$ volumetric fraction rapeseed biodiesel in its composition. In Romania, large rapeseed crops are cultivated. For the experiments developed in this study, the rapeseed biodiesel was obtained from an authorized local supplier. The fuel complies with the European standard EN 14214. Table 3 displays some physicochemical properties of fuels used in the present study.

Table 3. Physio-chemical properties of diesel fuel D100 and biofuels B100 and B20 [24].

\begin{tabular}{ccccccccc}
\hline Fuel & $\begin{array}{c}\text { Density } \\
\left(\mathbf{g} / \mathbf{c m}^{\mathbf{3}}\right) \\
\mathbf{2 0} \mathbf{C}\end{array}$ & $\begin{array}{c}\text { Cold Filter } \\
\text { Plugging } \\
\text { Point }\left({ }^{\circ} \mathbf{C}\right)\end{array}$ & $\begin{array}{c}\text { Viscosity } \\
(\mathbf{c S t}) \mathbf{2 0}{ }^{\circ} \mathbf{C}\end{array}$ & $\begin{array}{c}\text { Pour Point } \\
\left({ }^{\circ} \mathbf{C}\right)\end{array}$ & $\begin{array}{c}\text { Flash Point } \\
\left({ }^{\circ} \mathbf{C}\right)\end{array}$ & $\begin{array}{c}\text { Lower } \\
\text { Heating Value } \\
\mathbf{( M J} / \mathbf{k g})\end{array}$ & $\begin{array}{c}\text { Cetane } \\
\text { Number }\end{array}$ & $\begin{array}{c}\text { Cloud } \\
\text { Point }\left({ }^{\circ} \mathbf{C}\right)\end{array}$ \\
\hline D100 & 0.8200 & -24 & 2.53 & -24 & 58.5 & 41.87 & 51.1 & -16 \\
B100 & 0.8864 & -2 & 8.06 & -7 & 184 & 37.34 & 53.5 & -4 \\
B20 & 0.8565 & -24 & 5.12 & -18 & 85 & 40.59 & 52.5 & -10 \\
\hline
\end{tabular}




\section{Simulation Details}

The assessment of the injection rate shape effects on performance and emissions was made by simulation using the AVL BOOST software including the AVL MCC combustion model (mixing controlled combustion). This model evaluates the rate of heat release in direct injection compression ignition (DICI) engines [25]. The $\mathrm{NO}_{x}$ formation is based on the extended Zeldovich mechanism coupled with three additional reactions for $\mathrm{N} 2 \mathrm{O}$ formation. The Soot estimation is performed by a mechanism consisting of two reactions of formation and oxidation which are based on chemical kinetics. The AVL MCC model requires the introduction of specific values for some physical properties and several normalised model parameters. Figure 2 shows the symbolic model of the engine and the AVL MCC normalized parameters.

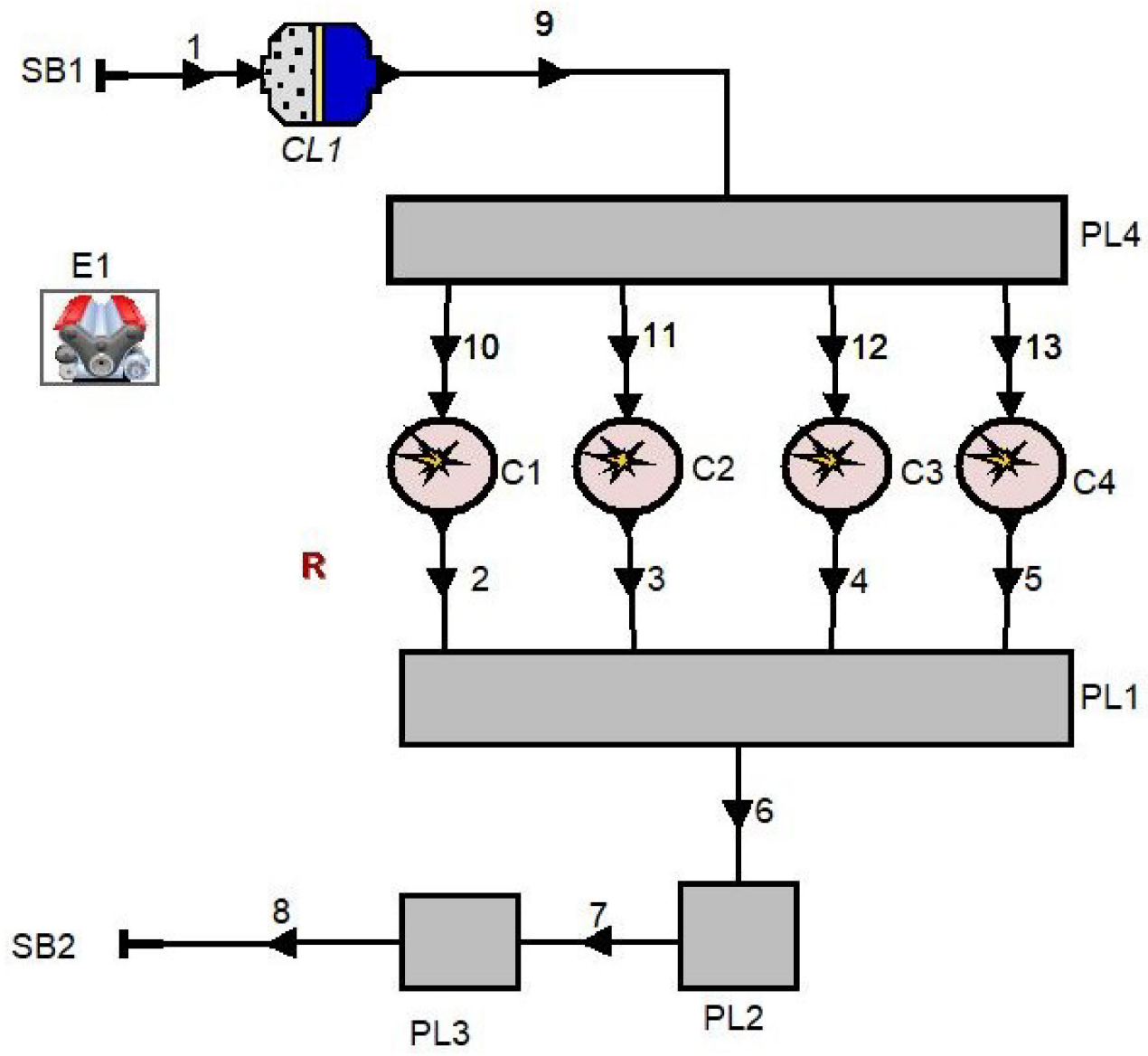

Figure 2. Symbolic model of the diesel engine under test.

The model calibration was performed for the Top-Hat (TH) shape of the rate of injection (ROI). Table 4 shows the values adopted and introduced in the AVL MCC combustion model for the normalized parameters and the physical data corresponding to both fuels and engine operating conditions.

An initial stage of the simulation study consisted in the model calibration. This was done based on the comparison made between the experimental and simulated in-cylinder pressure traces and the values of engine parameters expressing performance (brake power$\mathrm{BP})$, efficiency (brake-specific fuel consumption (BSFC)) and emissions (nitrogen oxides$\mathrm{NO}_{\mathrm{x}}$ and Soot). The relative deviations for all parameters considered relevant to the model calibration remained below $3 \%$ for both tested fuels and engine operating conditions, as shown in Table 5. 
Table 4. The values adopted for the normalized parameters and physical properties of the AVL MCC.

\begin{tabular}{|c|c|c|c|c|c|}
\hline & \multirow{2}{*}{$\begin{array}{c}\text { Operating Point } \\
\text { Fuel }\end{array}$} & \multicolumn{2}{|c|}{ R1 (Full Load, 1400 rpm) } & \multicolumn{2}{|c|}{ R2 (Full Load, 2400 rpm) } \\
\hline & & D100 & B20 & D100 & B20 \\
\hline \multirow{5}{*}{$\begin{array}{l}\text { Normalised Model } \\
\text { Parameters }\end{array}$} & Ignition Delay Calibration Factor [-] & 0.68 & 0.62 & 0.5 & 0.49 \\
\hline & Combustion Parameter [-] & 0.76 & 0.685 & 0.74 & 1.17 \\
\hline & Turbulence Parameter [-] & 1 & 1 & 2 & 1 \\
\hline & Dissipation Parameter [-] & 1 & 1 & 0.0001 & 1 \\
\hline & Premixed Combustion Parameter [-] & 0.65 & 0.65 & 0.9 & 0.7 \\
\hline & Number of Injector Holes [-] & \multicolumn{4}{|c|}{5} \\
\hline Physical & Hole Diameter [mm] & \multicolumn{4}{|c|}{0.24} \\
\hline Data & Discharge Coefficient [-] & \multicolumn{4}{|c|}{0.5} \\
\hline & Rail Pressure [bar] & \multicolumn{4}{|c|}{350} \\
\hline
\end{tabular}

The experimental pressure traces and the numerically determined temperature and pressure curves are revealed in Figure 3. It shows a normal variation of cylinder charge temperature by crankshaft position with the maximum values reached after TDC for both engine operating conditions and tested fuels. It can be noticed that the peak in-cylinder temperature has higher values for diesel fuel than for biodiesel B20, regardless of the engine operating condition.

Table 5. The calibration of the simulation model.

\begin{tabular}{|c|c|c|c|c|c|c|}
\hline & \multicolumn{3}{|c|}{ Diesel Fuel } & \multicolumn{3}{|c|}{ B20 } \\
\hline & $\begin{array}{c}\text { Experimental } \\
\text { Data } \\
\text { R1/R2 }\end{array}$ & $\begin{array}{l}\text { AVL MCC } \\
\text { Results } \\
\text { R1/R2 }\end{array}$ & $\begin{array}{c}\text { Relative } \\
\text { Deviations [\%] } \\
\text { R1/R2 }\end{array}$ & $\begin{array}{c}\text { Experimental } \\
\text { Data } \\
\text { R1/R2 }\end{array}$ & $\begin{array}{l}\text { AVL MCC } \\
\text { Results } \\
\text { R1/R2 }\end{array}$ & $\begin{array}{c}\text { Relative } \\
\text { Deviations [\%] } \\
\text { R1/R2 }\end{array}$ \\
\hline $\mathrm{BP}[\mathrm{kW}]$ & $32.87 / 47.37$ & $32.22 / 46.09$ & $-1.98 /-2.70$ & $31.73 / 46.33$ & $32.21 / 45.56$ & $1.51 /-1.66$ \\
\hline BSFC $[\mathrm{g} / \mathrm{kWh}]$ & $236.39 / 255.01$ & $241.21 / 262.08$ & $2.04 / 2.77$ & $254.96 / 264.62$ & $251.18 / 269.14$ & $-1.48 / 1.71$ \\
\hline $\mathrm{p}_{\max }[\mathrm{bar}]$ & $66.53 / 64.63$ & $66.15 / 64.28$ & $-0.57 /-0.54$ & $66.07 / 64.05$ & $65.48 / 64.02$ & $-0.89 /-0.05$ \\
\hline $\mathrm{NO}_{\mathrm{x}}[\mathrm{ppm}]$ & $1082 / 640$ & $1083.41 / 640.17$ & $0.13 / 0.03$ & $1017 / 727$ & $1017.53 / 727.37$ & $0.05 / 0.05$ \\
\hline Soot $[\mathrm{g} / \mathrm{kWh}]$ & $2.1661 / 1.5430$ & $2.1666 / 1.5434$ & $0.02 / 0.03$ & $2.0507 / 1.4403$ & $1.9939 / 1.4027$ & $-2.77 /-2.61$ \\
\hline$\lambda[-]$ & $1.35 / 1.55$ & $1.37 / 1.52$ & $1.48 /-1.94$ & $1.43 / 1.59$ & $1.44 / 1.63$ & $0.70 / 2.52$ \\
\hline
\end{tabular}

A next stage of the simulation work consisted in modifying the shape of the original injection rate (Top-Hat) by keeping the same area, initiation event (start of injection-SOI) and duration up to the end of the injection (EOI). The following acronyms of the ROI shapes are applied: Top-Hat (TH); Isosceles Trapezoid (IT); Right Trapezoid (RT); Triangle 1 (TR1); Triangle 2 (TR2); Triangle 3 (TR3); Boot 1 (BO1); Boot 2 (BO2).

The ROI variations relative to the crankshaft angular position are illustrated in Figure 4. The start of injection and the end of injection (SOI/EOI) were considered as $-5^{\circ} \mathrm{CA} / 11^{\circ} \mathrm{CA}$ for R1 (full load, $1400 \mathrm{rpm}$ ) and, respectively, $-5.5^{\circ} \mathrm{CA} / 13^{\circ} \mathrm{CA}$ for R2 (full load, $2400 \mathrm{rpm}$ ). Both events were related to the top dead center end of compression (TDC). 


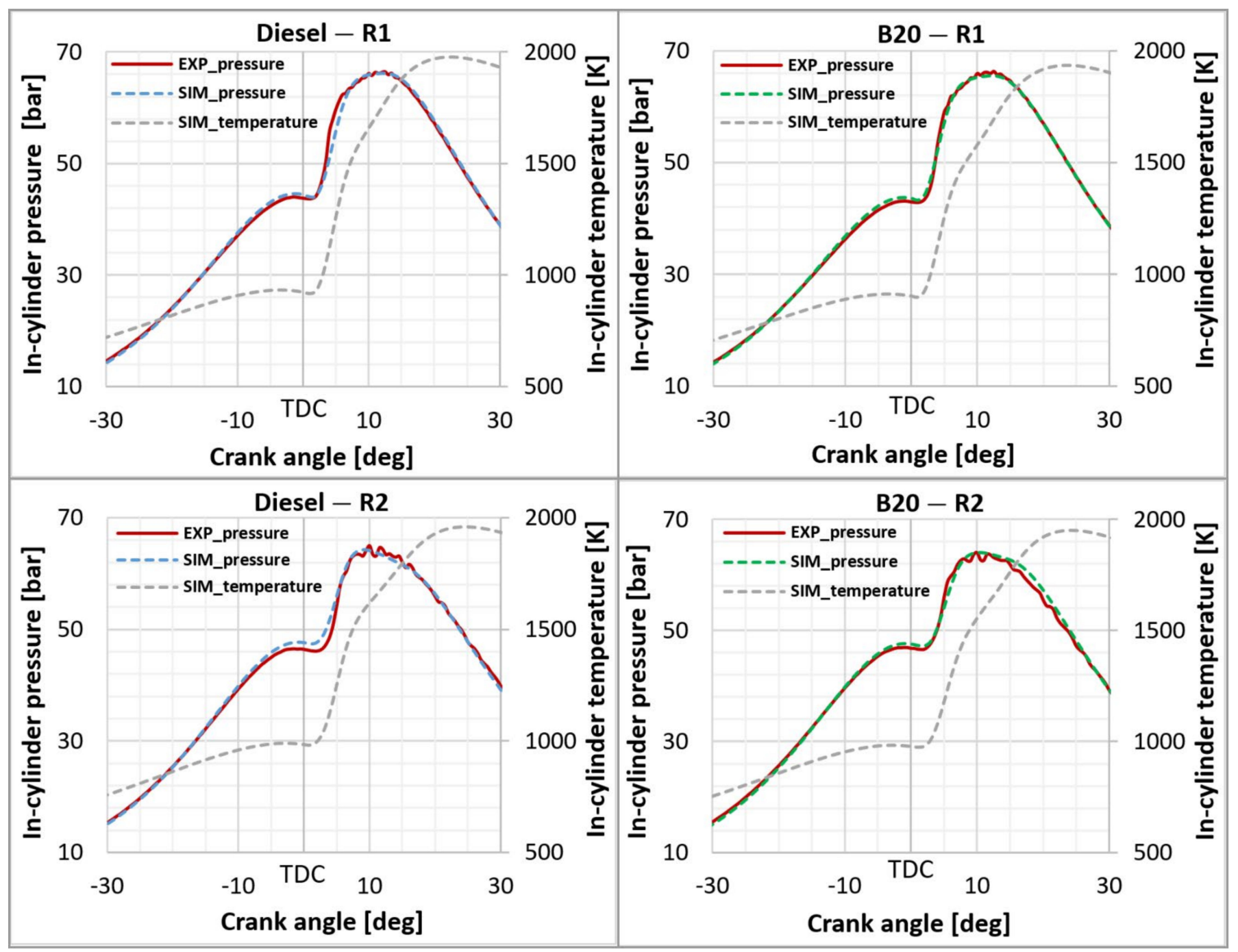

Figure 3. Pressure traces calibration and temperature variations for both engine operating conditions and tested fuels.
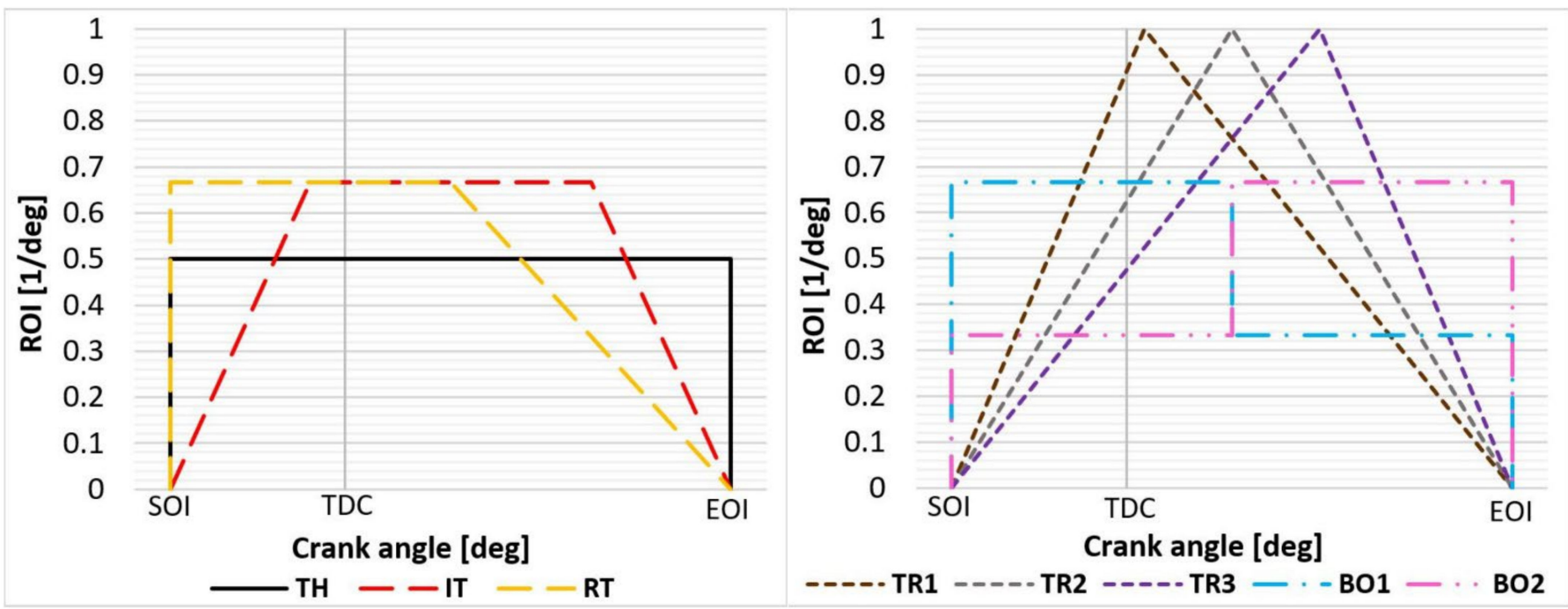

Figure 4. Original and modified rate of injection shapes under simulation study. 


\section{Results and Discussion}

Simulations were performed for all ROI shapes considered, using both fuels for both engine test conditions. The relative deviations presented in the comments of Figures 5-14 were calculated relative to the Top-Hat shape of ROI as reference.

Figure 5 illustrates the values of the ignition delay dependent on the ROI shape. The ignition delay in a diesel engine represents the duration between the start of injection and the start of combustion (SOC). In this study, the SOC was defined by the zero value of the rate of heat release. As seen in the following figure, the ignition delay is slightly influenced by the ROI shape and confirms the results from [11]. As it depends on the physical parameters, namely the cylinder charge pressure and temperature during the injection timing, respectively on the chemical parameters, such as fuel chemical composition and structure, fuel cetane number, it can be noticed a very small variation of this parameter relative to the ROI shape. Because the percentage of biodiesel in the B20 composition is low and its cetane number is approximately the same as diesel fuel, the differences for ignition delay between these two fuels are small. Concerning the ignition delay in [18,21], where the considered shapes of injection rates are somehow different relative to those from this study, not equivalent results have been obtained for diesel fuel, kerosene, and kerosene-diesel blends.

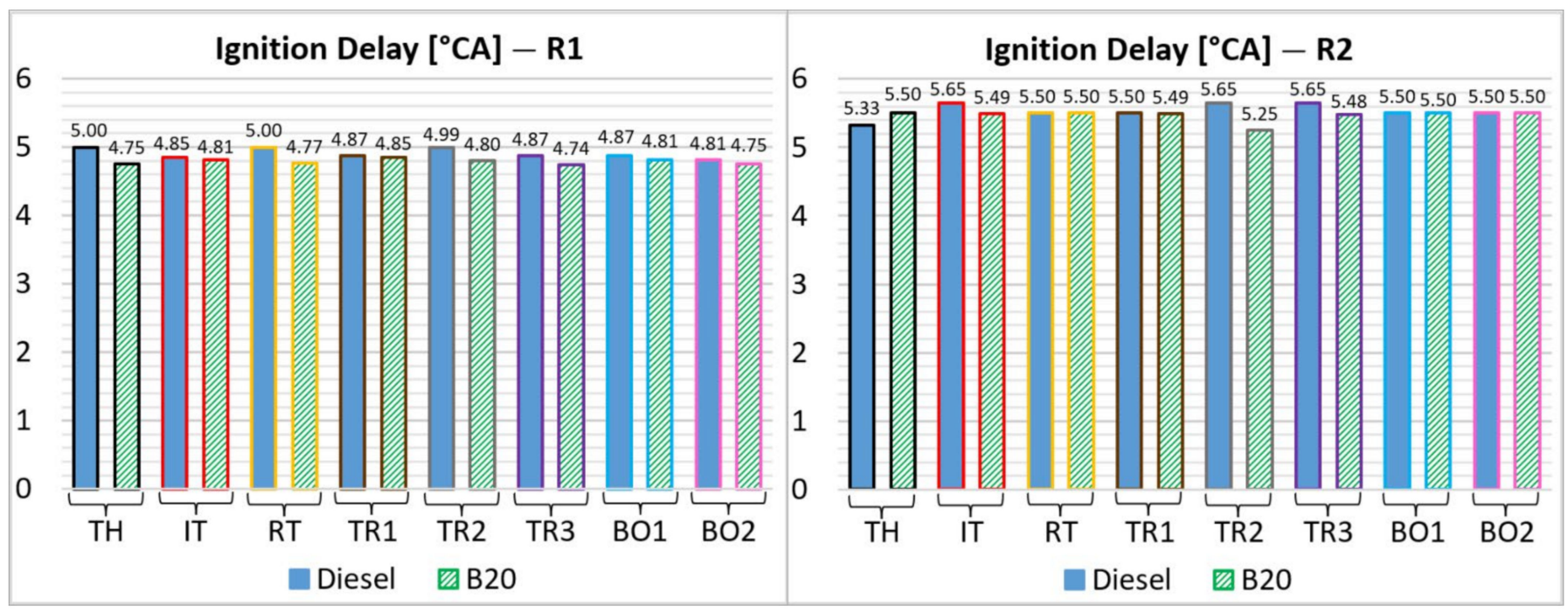

Figure 5. Ignition delay variation by different shapes of ROI.

In Figure 6 are shown the evolutions of the initial combustion phase relative to the ROI shape. The initial combustion stage is characterized by the combustion of the premixed charge, being considered as the period between the start of combustion and the event when $10 \%$ of the mass fraction is burned (MFB10\%). This period is strongly influenced by the amount of fuel injected, accumulated, vaporized, and mixed with air during the ignition delay. For the R1 engine test condition, the minimum values are obtained using the $\mathrm{BO} 1$ shape with a reduction of $14.6 \%$ for diesel fuel and $13.9 \%$ for B20 relative to the considered reference shape $(\mathrm{TH})$. For the $\mathrm{R} 2$ test condition, the minimum values are obtained when using the same BO1 shape with a reduction of $9.3 \%$ for diesel fuel and, respectively, $11.9 \%$ for $\mathrm{B} 20$. The maximum values on the $\mathrm{R} 1$ test condition are obtained using the $\mathrm{BO} 2$ shape with an increase of $20.9 \%$ for diesel fuel and $23.1 \%$ for B20, while on the R2 these are obtained using the TR3 shape with an increase of 36.4\% for diesel fuel and 23.3\% for B20. This finding could be explained by the lesser fuel quantity injected during the ignition delay. The values of the initial combustion stage are comparable, having approximately similar variations for both fuels. 


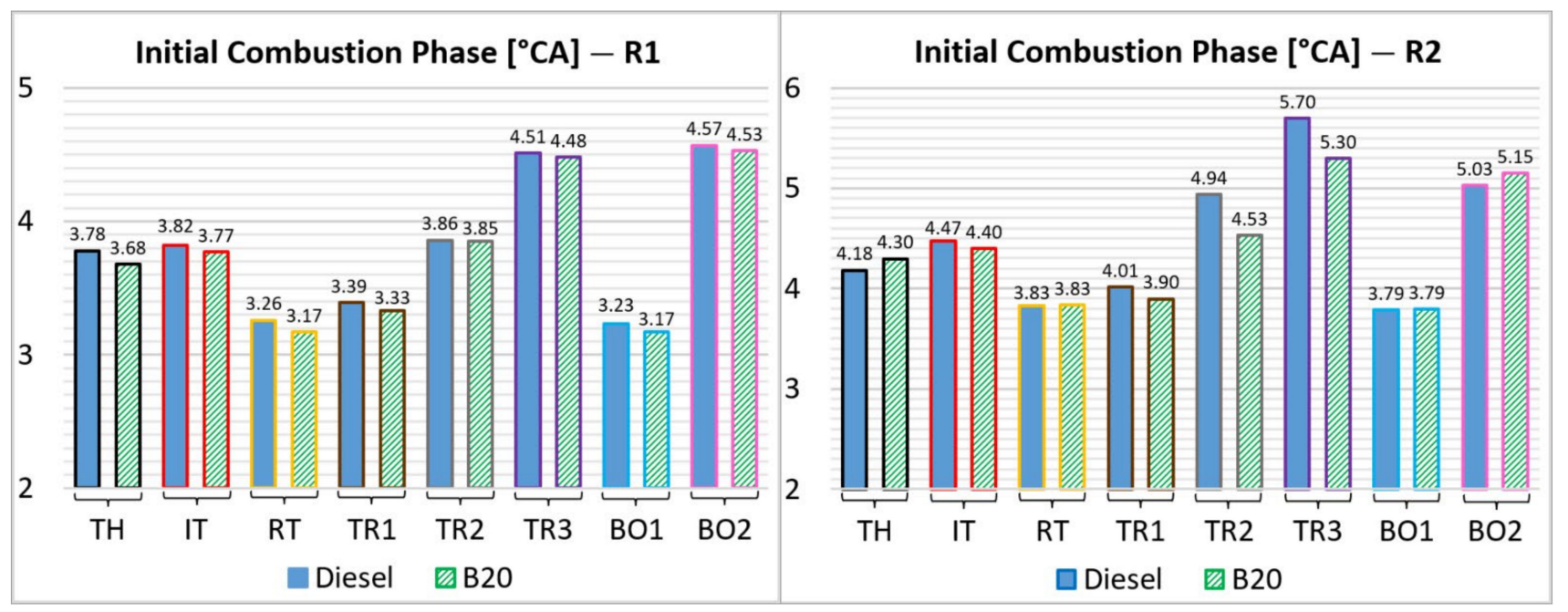

Figure 6. Initial combustion phase variation by different shapes of ROI.

Figure 7 shows the values of total combustion duration versus the ROI shape. The combustion duration is considered as the interval between the start of combustion and the instant when $95 \%$ of the mass fraction is burned. The minimum values are obtained for the TR1 shape with a reduction of $34.8 \%$ for diesel fuel at both engine test conditions (R1 and R2) and $36 \%$ for B20 at R1, respectively, 34.3\% at R2. It can thus be pointed out that triangular shapes ensure the fastest combustion by promoting the premixed phase, which clearly explains the occurrence of the highest peak in-cylinder temperatures among the studied ROI shapes (Figure 8). For both fuels, the maximum combustion duration is reached when using the TH shape. A constant fuel injection speed leads to a longer combustion duration because the fuel is evenly distributed throughout the whole injection process compared to a fast injection when a high amount of fuel concentrates over a certain part of the injection process, which causes a short combustion duration. In such conditions, the combustion process is shifted towards a slower mixing-controlled combustion phase. When using B20 instead of diesel, the fuel mass flow increases by $4.1 \%$ for R1 and only by $1.5 \%$ for R2. If considering the lower heating value of the fuels, the energy released per cycle is higher when using B20 than using diesel fuel for R1 and lower for R2, which involves a longer combustion duration for R1 and a shorter one for R2. Concerning the influence of the rate of injection shape on combustion duration, comparable results have been reported in $[14,18,20]$ when using diesel fuel.

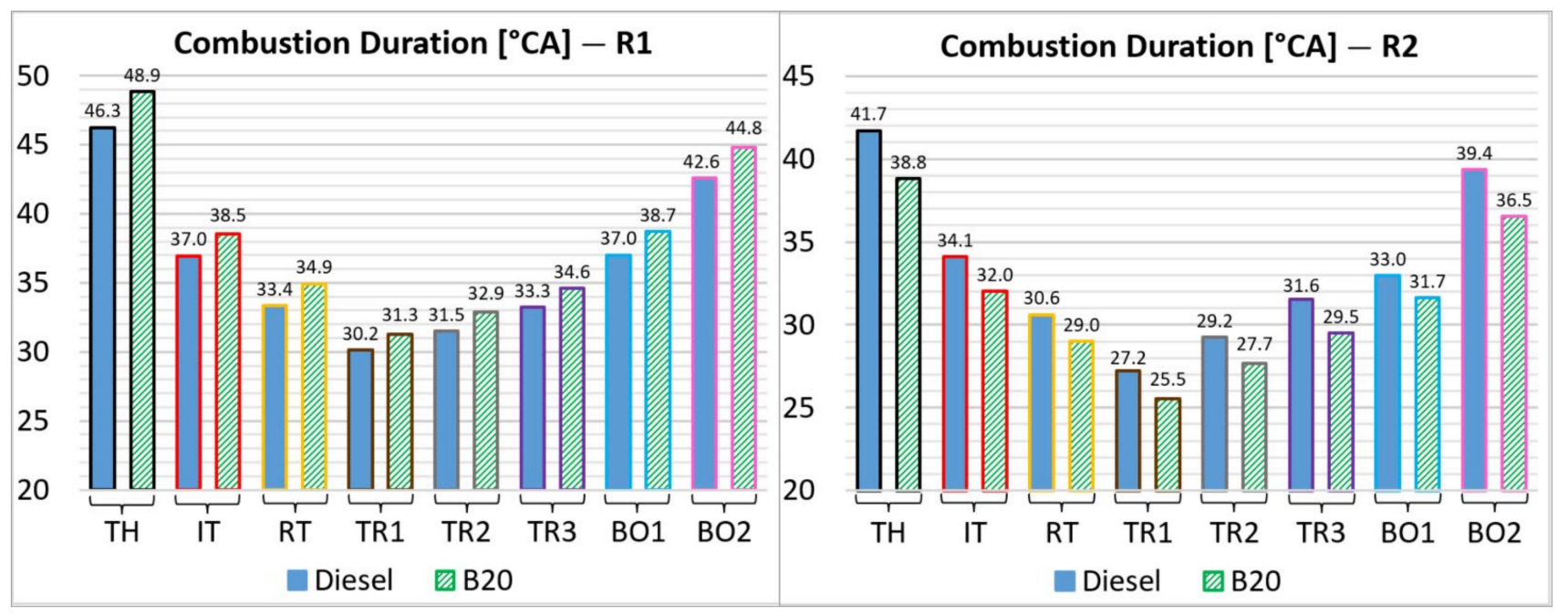

Figure 7. Combustion duration variation by different shapes of ROI. 
In Figure 8 are displayed the values of peak in-cylinder temperature versus the ROI shape. The maximum values are obtained for the TR1 shape with an increase of $7 \%$ for diesel fuel, 6.7\% for B20 on R1 and, respectively, 7.6\% for diesel fuel, $6.2 \%$ for B20 on R2 relative to the reference $\mathrm{TH}$ shape. The minimum values are reached for the reference shape that was used for the model calibration. The shapes which promote the premixed combustion determine higher peak in-cylinder temperatures contrary to the $\mathrm{TH}$ and $\mathrm{BO} 2$ shapes, which develop the diffusive combustion. The values obtained when using diesel fuel are constantly greater than those achieved when using B20 due to the lower heating value, which is higher for diesel fuel than for B20 (41.87 MJ/kg compared to $40.59 \mathrm{MJ} / \mathrm{kg}$ ). Similar results regarding the influence of the rate of injection shape on the peak in-cylinder temperature when using diesel fuel were reported in [14,15,22].

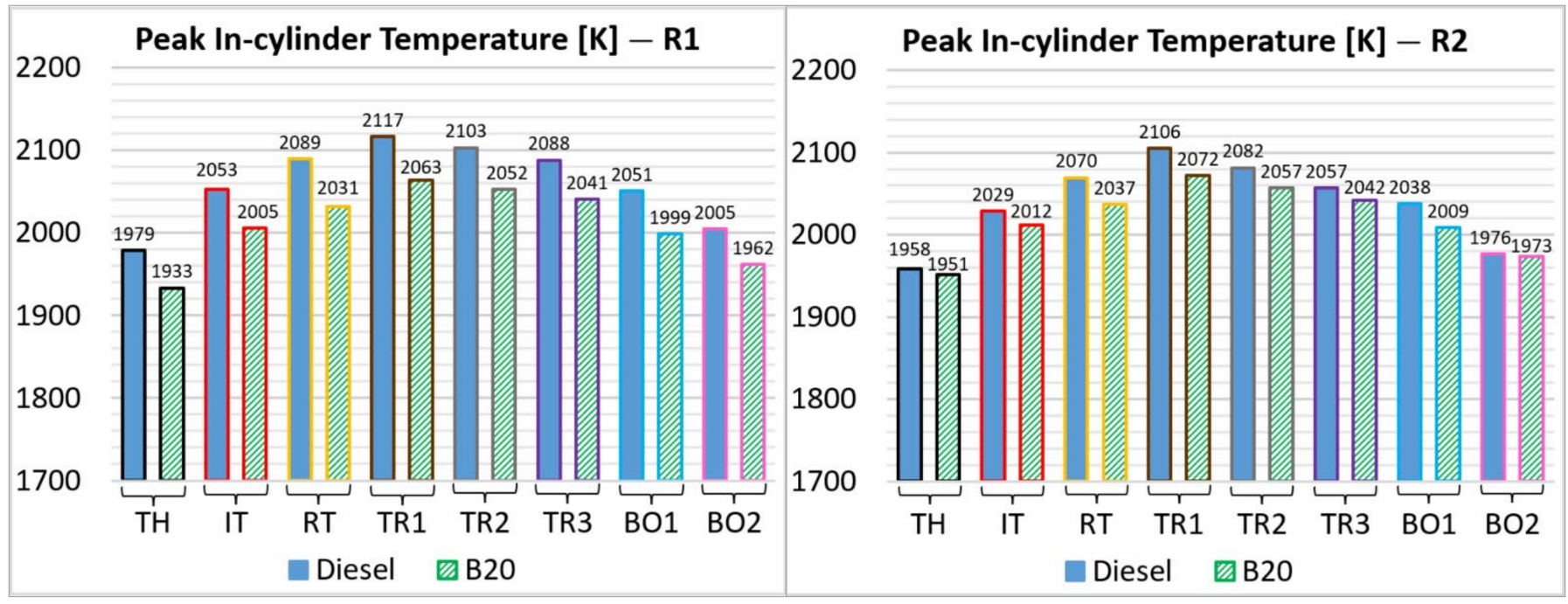

Figure 8. Peak in-cylinder temperature variation by different shapes of ROI.

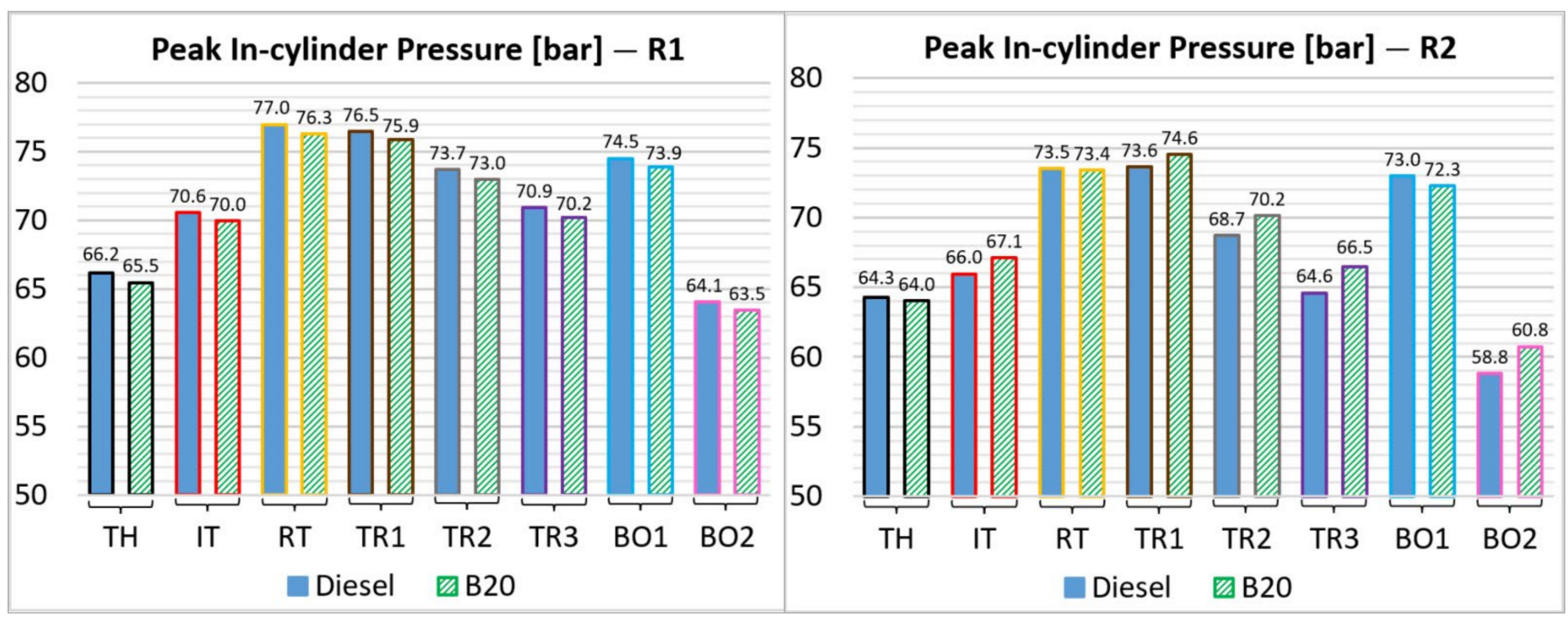

Figure 9. Peak in-cylinder pressure variation by different shapes of ROI.

Figure 9 shows the dependence of peak in-cylinder pressure values on the ROI shape. The minimum values are reached for the $\mathrm{BO} 2$ shape with decreases of $3.1 \%$ for both fuels on the R1 operating condition, respectively $8.6 \%$ for diesel fuel and $5 \%$ for B20 on R2 because most of the fuel is late injected, at the beginning of the expansion stroke. For the R1 condition, the highest values are obtained with the RT shape presenting increases of 
$16.3 \%$ for diesel fuel and $16.5 \%$ for B20. For the R2 condition, such maximal values are obtained with the TR1 shape showing increases of $14.5 \%$ for diesel fuel and $16.6 \%$ for B20. The maximum values are reached for these shapes, because the fuel amount is rapidly injected at the end of the compression stroke compared to the other shapes. Comparable results on the peak in-cylinder pressure for diesel fuel were reported in $[7,15,18,20,21,23]$ for biodiesel usage. The increase in thermal efficiency when using triangular shapes is also reported in [18].

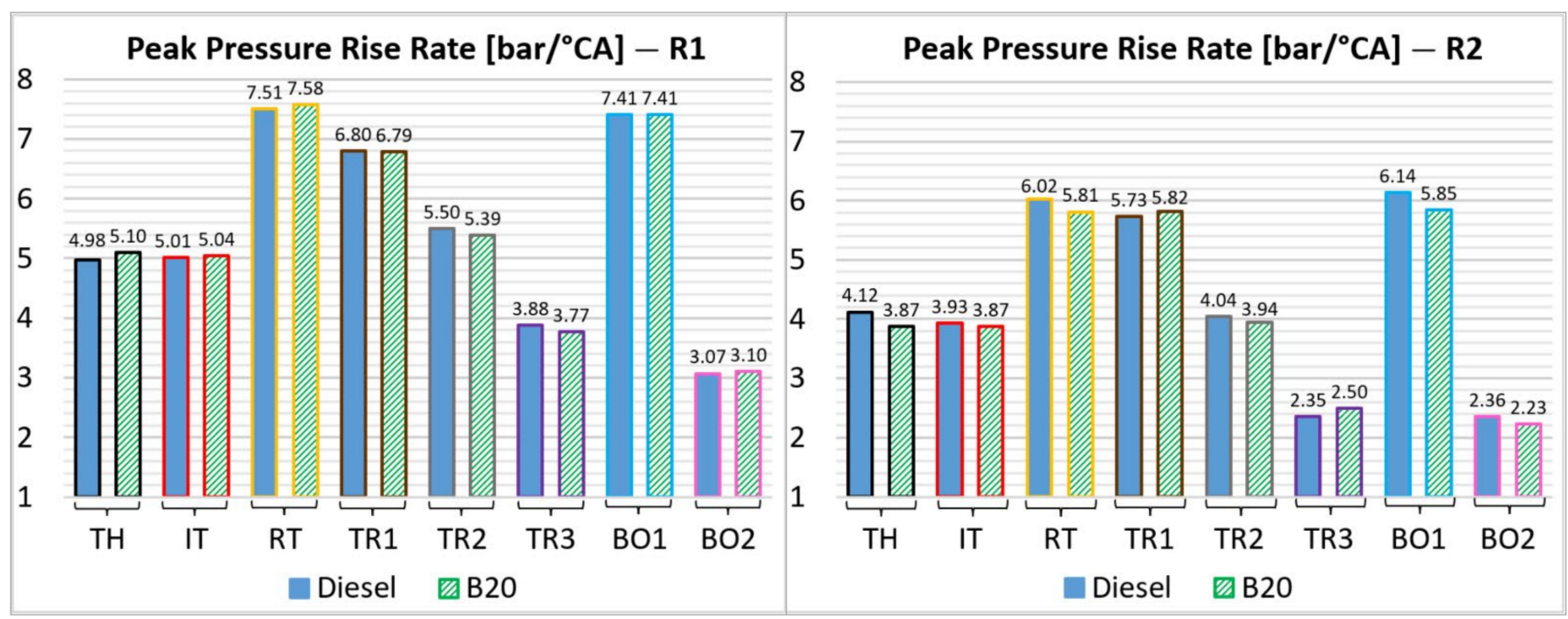

Figure 10. Peak in-cylinder pressure rise rate variation by different shapes of ROI.

It is known that the peak in-cylinder pressure rise rate has a strong influence on the engine noise. Figure 10 exhibits the values of this parameter relative to the ROI shape. For the same reason mentioned in the comments of Figure 9, the minimum values of peak pressure rise rate are obtained by using the $\mathrm{BO} 2$ shape with reductions of $38.4 \%$ for diesel fuel and $39.2 \%$ for B20 on the R1 condition, respectively of $42.7 \%$ for diesel fuel and $42.4 \%$ for $\mathrm{B} 20$ on the R2 condition. The maximum values are achieved on the R1 when using the RT shape displaying increases of $50.8 \%$ for diesel fuel and $48.6 \%$ for B20, while on the R2 by using the BO1 shape, the increases are $49 \%$ for diesel fuel and, respectively, $51.2 \%$ for B20. Similar conclusions regarding the influence of the rate of injection shape on peak pressure rise rate when using diesel fuel were reported in [18]. It was emphasized that triangular rate-shape injections give higher in-cylinder pressure rise rates as compared to ramp rate-shape injections and, furthermore, the injection rate shaping causes combustion phasing to occur.

In Figure 11 are displayed the values of brake power versus the ROI shape. It can be noticed that, for the R1 operating condition, all the triangular shapes offer maximum performance in respect to the reference $\mathrm{TH}$ shape with an average increase of $3 \%$ for diesel fuel and B20. At the same time, similar results are registered with the TR1 shape on the R2 operating condition, with an increase of $4.6 \%$ for diesel fuel and $3.5 \%$ for B20. These results occurred because, for all triangular shapes, the combustion durations are shorter and the combustion process is well situated relative to the region with minimum cylinder volume variation, leading thus to higher peak in-cylinder temperatures and increased efficiency values of engine operation. Using the BO2 shape, lower power was obtained. The brake power has almost the same value for both fuels on the R1 test condition, because the increase in fuel consumption of $4.1 \%$ when fuelling with B20 relative to diesel fuel is high enough to compensate for the decrease of $3.1 \%$ in the lower heating value. However, in the R2 operating state, the increase in fuel consumption of B20 is only $1.5 \%$ and this cannot compensate for its reduced lower heating value, the brake power standing smaller for all the injection shapes considered. 


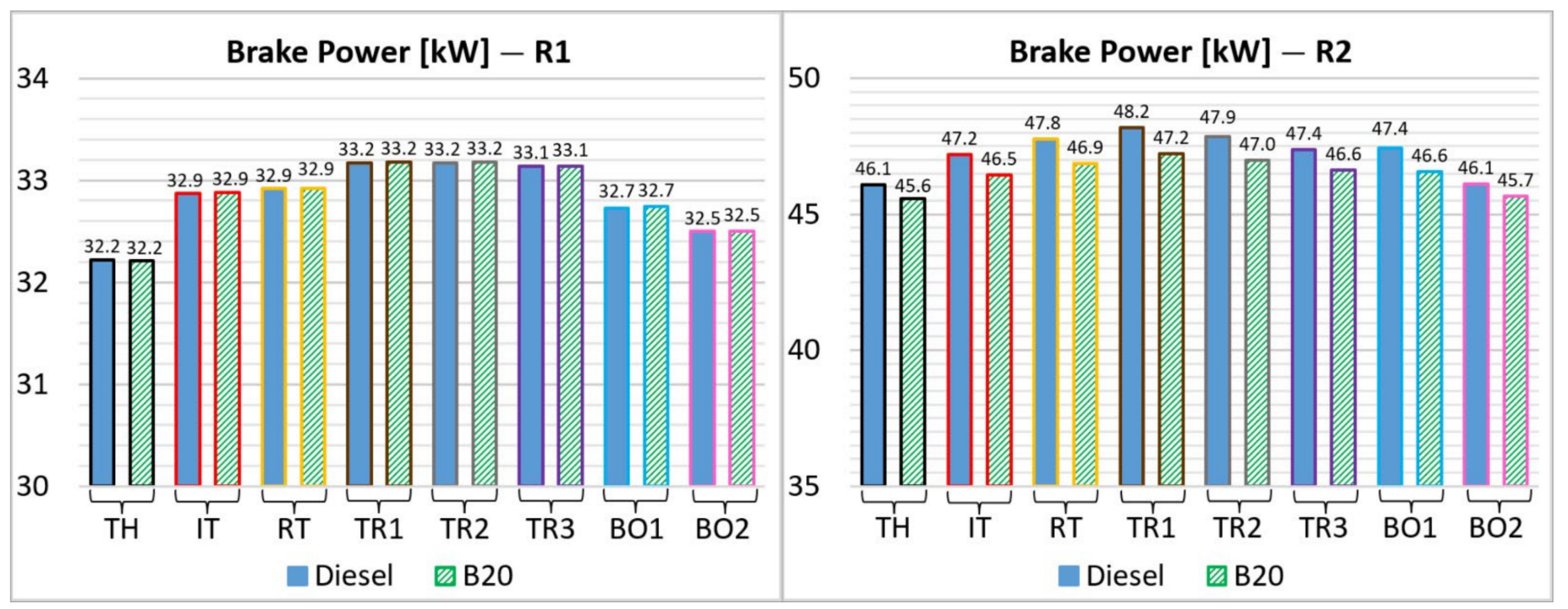

Figure 11. Brake power variation by different shapes of ROI.

The variation of brake-specific fuel consumption (BSFC) generated by the alteration of the injection rate shape is presented in Figure 12. The triangular shapes offering the highest engine brake power involve the lowest values of BSFC (high performance and efficiency). For these shapes, on R1 there are reductions in BSFC of 2.9\% for both fuels, and for TR1 on R2 the reductions are $4.3 \%$ for diesel fuel, respectively of 3.5\% for B20. The TH and $\mathrm{BO} 2$ shapes with minimum performances lead to maximum values of BSFC. There are not practically significant differences in the BSFC variation with the ROI shapes for B20 relative to diesel fuel, because the altering of the ROI shape does not significantly change the brake power variation when switching from diesel fuel to B20. The slightly elevated values of BSFC in the case of B20 usage, for all the ROI shapes considered, are determined by the higher amounts of fuel injected. The physical properties of biodiesel, notably viscosity and density, are responsible for the higher injected amounts of B20 fuel. In [13], it was also highlighted that the boot-like rate shapes which concentrate higher amounts of fuel at the end of the injection process produce a general increase in BSFC.

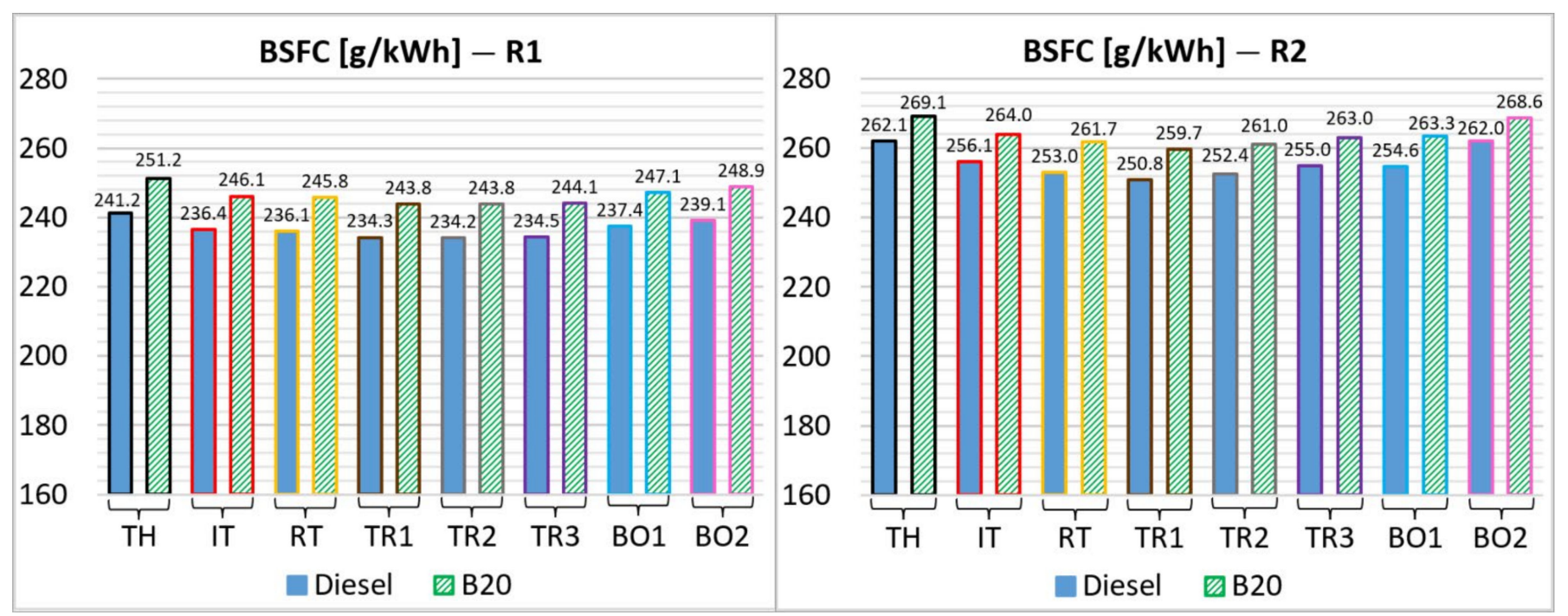

Figure 12. Brake-specific fuel consumption (BSFC) variation by different shapes of ROI.

Figure 13 shows the variation of nitrogen oxides $\left(\mathrm{NO}_{\mathrm{x}}\right)$ emissions depending on the ROI shape. The minimum values are obtained for the $\mathrm{BO} 2$ shape with decreases of $17.2 \%$ 
for diesel fuel and $11.2 \%$ for B20 on R1. Higher reductions of $27.8 \%$ for diesel fuel and $21.7 \%$ for B20 are registered on R2 due to the combined effect of smaller peak in-cylinder temperatures and the development of diffusion combustion. The maximum values of $\mathrm{NO}_{\mathrm{x}}$ are obtained for RT and TR1 shapes with average increases on R1 by $47.4 \%$ for diesel fuel, and $40.4 \%$ for B20, respectively on R2 by $62.3 \%$ for diesel fuel, and $55 \%$ for B20, because, with these shapes, the highest values of peak in-cylinder temperature are attained. For the $\mathrm{R} 2$ test condition, although the peak in-cylinder temperatures are lower when using B20 than diesel fuel, the $\mathrm{NO}_{\mathrm{x}}$ emissions are higher due to its superior oxygen content. However, this effect is overpassed, and the trend is reversed in the case of the R1 test condition because of the elevated differences existing between the two fuels in terms of peak cylinder temperatures and combustion durations. Comparable results regarding the $\mathrm{NO}_{\mathrm{x}}$ emissions when using diesel fuel were reported in $[9,10,12,13,15,18,21,22]$. However, different results are presented in [7], where, for some increases applied at the beginning of the injection rate on certain boot shapes, the decrease of $\mathrm{NO}_{\mathrm{x}}$ emissions was registered.

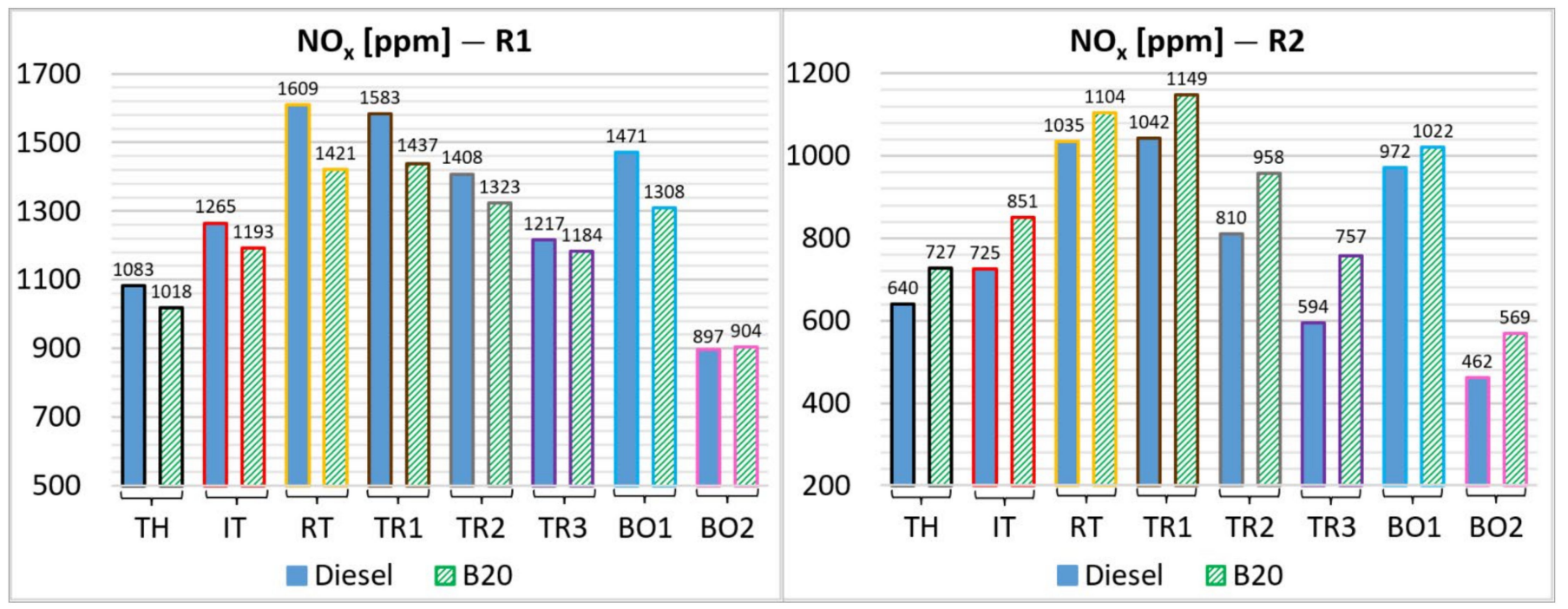

Figure 13. Nitrogen oxides $\left(\mathrm{NO}_{\mathrm{x}}\right)$ variation by different shapes of ROI.

Figure 14 exhibits the values of Soot emissions relative to the ROI shapes. The minimum values are obtained for the TR1 shape with reductions of $43.8 \%$ for diesel fuel and $33.2 \%$ for B20 on R1. For the other operating condition R2, the Soot reduction with the TR1 shape relative to the $\mathrm{TH}$ is $63 \%$ for diesel fuel and, respectively, $47.1 \%$ for B20. The ROI shapes, which concentrate a large amount of fuel injected up to the ignition time, enhance the mixing process and promote faster burning rates, which lead to higher $\mathrm{NO}_{\mathrm{x}}$ and lower Soot emissions. For both fuels, the maximum Soot values are obtained with the TH shape. Similar results on Soot emissions for diesel fuel usage have been reported in $[9,10,13,15,22]$. Nevertheless, some different results were presented in [7], where, for increased values of injection rate at the beginning of the injection process on certain boot shapes, higher Soot emissions were disclosed.

As previously noted, the premixed combustion phase significantly influences the $\mathrm{NO}_{\mathrm{x}}$ and Soot emissions generation process. In this sense, a final part of this study was dedicated to the link existing between the amount of fuel injected in the initial stage of combustion and the values of pollutant emissions. For such analysis, the connection existing between the surface area under the ROI shapes (between the SOI- and MFB10\% events) and the magnitude of $\mathrm{NO}_{\mathrm{x}}$ and Soot emission values was evaluated. The calculated values of surface area are presented in Table 6 for each ROI shape. The BO1, RT and TR1 shapes presented relative to the TH reference shape higher values of this surface area with average increases for both fuels of $25.8 \%, 24 \%$ and $19.2 \%$ on the R1 operating condition and, respectively, of $28.1 \%, 25.7 \%$ and $26.5 \%$ for the R2 test condition. 


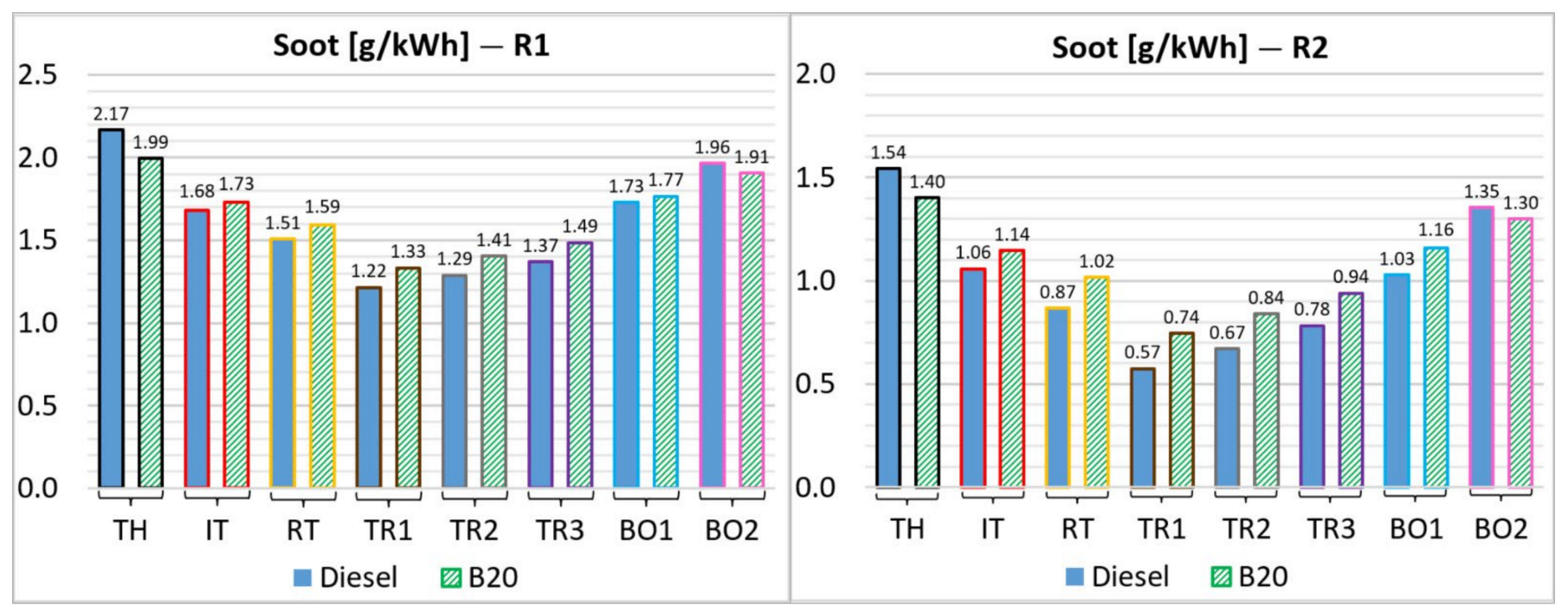

Figure 14. Soot variation by different shapes of ROI.

Table 6. The surface area under the ROI shapes calculated between the SOI and MFB10\% events.

\begin{tabular}{ccccc}
\hline \multirow{2}{*}{ ROI Shape } & \multicolumn{2}{l}{$\begin{array}{l}\text { R1 (Full Load, 1400 rpm) } \\
\text { SOI-MFB10\% Surface [-] }\end{array}$} & \multicolumn{2}{c}{$\begin{array}{l}\text { R2 (Full Load, 2400 rpm) } \\
\text { SOI-MFB10\% Surface [-] }\end{array}$} \\
\cline { 2 - 5 } & D100 & B20 & D100 & B20 \\
\hline TH & 4.39 & 4.22 & 4.76 & 4.90 \\
IT & 4.46 & 4.40 & 5.20 & 5.05 \\
RT & 5.50 & 5.30 & 6.06 & 6.06 \\
TR1 & 5.16 & 5.10 & 6.14 & 6.07 \\
TR2 & 4.81 & 4.63 & 5.61 & 5.15 \\
TR3 & 4.20 & 4.06 & 4.70 & 4.49 \\
BO1 & 5.37 & 5.32 & 6.18 & 6.18 \\
BO2 & 3.59 & 3.52 & 3.94 & 4.02 \\
\hline
\end{tabular}

Figure 15 shows the variations of $\mathrm{NO}_{\mathrm{x}}$ and Soot emissions versus this surface area of injected fuel amount during the initial combustion stage. The correlation which can be detected is practically linear for both engine operating conditions and both fuels. An increase of $53 \%$ in the injection area for diesel fuel on R1 (from 3.6 to 5.5) is leading to an increase of $76 \%$ in $\mathrm{NO}_{\mathrm{x}}$ on the trendline. A similar trend is registered for $\mathrm{B} 20$ too, but with a smaller increase of $50 \%$. The Soot variation is however reversed, its decrease being of $24 \%$ for diesel fuel and 16\% for B20 on the trendline, over the same range of the injection area. In the case of R2, the correlation remains linear, but it presents some differences existing between diesel fuel and biodiesel $\mathrm{B} 20$ mostly for $\mathrm{NO}_{\mathbf{x}}$. The slopes of linear correlation for $\mathrm{NO}_{\mathrm{x}}$ seem to have the same values for both fuels, but on B20, superior absolute values are registered. An increase of $57 \%$ of the injection area (from 3.9 to 6.2 ) is leading to a rise of $138 \%$ in $\mathrm{NO}_{\mathrm{x}}$ emissions on the trendline for diesel fuel. On the same domain of the injection area, the average growth of $\mathrm{NO}_{\mathrm{x}}$ emissions is smaller for $\mathrm{B} 20$, being around $86 \%$. The Soot variation remains quasi similar for both fuels with a dropping on the trendline by $43 \%$ for diesel fuel and, respectively, 21\% for B20. 


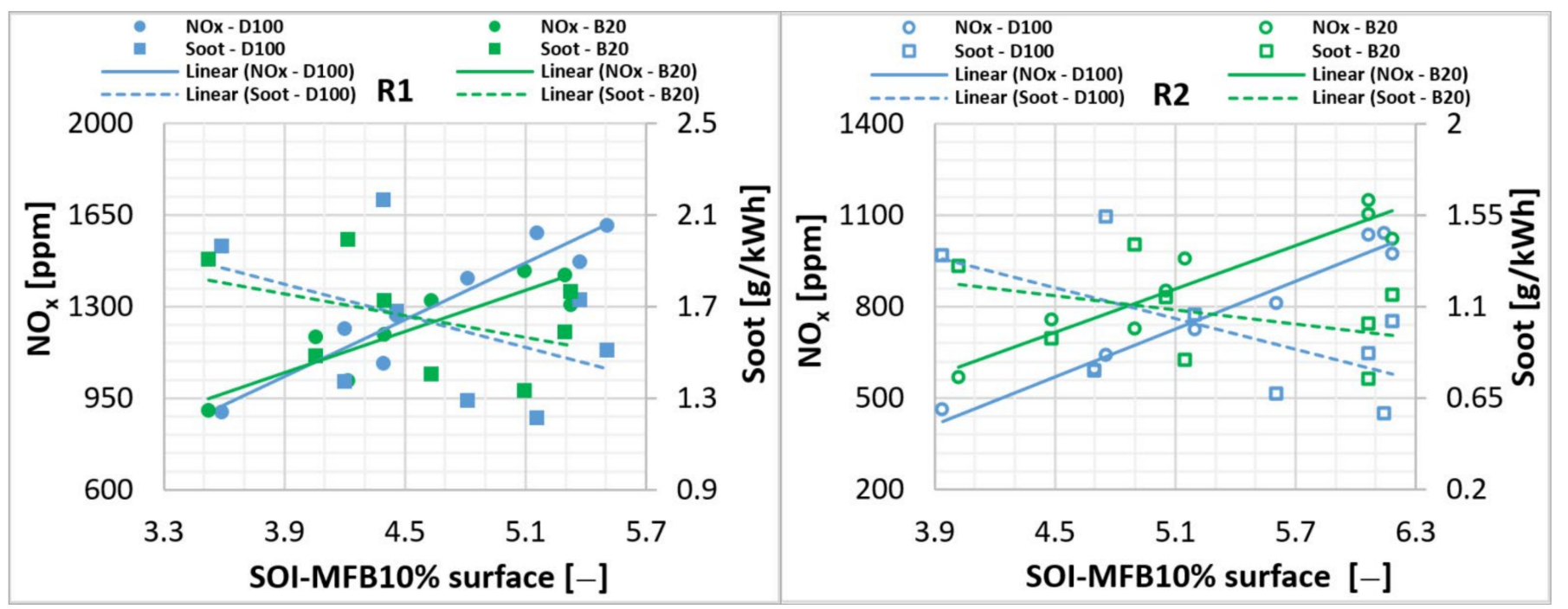

Figure 15. $\mathrm{NO}_{\mathrm{x}}$ and Soot trendlines variation relative to SOI-MFB10\% surface area.

\section{Conclusions}

A simulation study regarding the influences of using different injection rate shapes on the performance, efficiency and pollutant emissions of an agricultural tractor diesel engine fuelled with diesel fuel and biodiesel B20 and operating at maximum brake power and maximum brake torque test conditions has been conducted. In this sense, a simulation model in the AVL-BOOST software was developed, using the AVL-MCC combustion model, which was calibrated for the reference ROI shape (Top-Hat) using the experimentally recorded data.

Even though there are some specific limitations associated with the 1-D simulation model, concerning the prediction capacity of the differences existing between the values of the ignition delay when using different ROI shapes, the conclusions of this study can be summarized as follows:

- The variation of performance, efficiency and emission indicators with the ROI shape shows similar developments for both tested fuels (diesel fuel and biodiesel B20) and on both engine operating conditions (maximum brake torque at $1400 \mathrm{rpm}$, and maximum brake power at $2400 \mathrm{rpm}$ );

- The group of injection shapes presenting a fast increase of the injection rate at the beginning of the process (RT, TR1 and BO1) produces higher values of $\mathrm{NO}_{\mathrm{x}}$ emissions due to superior peak in-cylinder temperatures achieved by the development of the premixed rapid combustion. The group of shapes showing a fast increase of the injection rate at the end of the process (TR3 and $\mathrm{BO} 2$ ) produces smaller values of $\mathrm{NO}_{\mathrm{x}}$ emissions due to the development of the diffusion gradual combustion associated with moderate peak in-cylinder temperatures;

- $\quad$ The triangular ROI shapes (TR1, TR2 and TR3) concentrate a large amount of fuel up to the self-ignition time, which enhances mixing and determines faster burning rates, generates lower Soot emissions, better engine performance and efficiency for both fuels;

- $\quad$ Compared to the reference ROI shape (Top-Hat), the triangular TR3 shape produces only a slight increase of $\mathrm{NO}_{\mathrm{x}}$ emissions, but a significant decrease of Soot emissions, a higher engine brake output and a lower brake-specific fuel consumption;

- There is a quasi-linear correlation between the amount of fuel injected during the initial combustion stage and the values of $\mathrm{NO}_{x}$ and Soot emissions. The correlation shows that, the greater the injected fuel quantity, the higher the $\mathrm{NO}_{\mathrm{x}}$ emissions, and the Soot emissions are lower;

- The engine operation with the optimum injection rate shape (BO2-where the minimum surface calculated between the SOI and MFB10\% events is registered) involves a 
simultaneous reduction of $\mathrm{NO}_{x}$ and Soot emissions with $17 \%$, respectively $9 \%$ for diesel fuel on R1 test condition and with $28 \%$, respectively $12 \%$ on R2 test condition. The replacement of diesel fuel by biodiesel $\mathrm{B} 20$ produces similar reductions of $\mathrm{NO}_{\mathrm{x}}$ and Soot by $11 \%$, respectively $4 \%$ on $\mathrm{R} 1$ test condition and by $22 \%$, respectively $7 \%$ on R2 test condition.

The results obtained by this study show that an optimum shape of injection rate as the $\mathrm{BO} 2$ applied to a diesel engine may ensure the simultaneous reduction of $\mathrm{NO}_{\mathrm{x}}$ and Soot emissions without scarifying engine performances and efficiency even when the original diesel fuel is replaced by biodiesel B20.

Author Contributions: Conceptualization, R.C.; methodology, A.L.N. and R.C.; software, A.L.N. and R.C.; validation, A.L.N., R.C. and A.R.; formal analysis, A.L.N., R.C. and A.R.; investigation, R.C. and A.R.; resources, R.C. and A.R.; data curation, R.C. and A.R.; writing-original draft preparation, A.L.N., R.C. and A.R.; writing-review and editing, A.L.N., R.C. and A.R.; visualization, A.R.; supervision, R.C.; project administration, R.C.; funding acquisition, A.L.N. and R.C. All authors have read and agreed to the published version of the manuscript.

Funding: This research received no external funding.

Institutional Review Board Statement: Not applicable.

Informed Consent Statement: Not applicable.

Data Availability Statement: Not applicable.

Acknowledgments: The authors of this paper acknowledge the AVL-AST team from AVL List $\mathrm{GmbH}$ for the special support offered under the University Partnership Program on performing the simulation activity.

Conflicts of Interest: The authors declare no conflict of interest.

\section{References}

1. Di Blasio, G.; Vassallo, A.; Pesce, F.C.; Beatrice, C.; Belgiorno, G.; Avolio, G. The Key Role of Advanced, Flexible Fuel Injection Systems to Match the Future $\mathrm{CO}_{2}$ Targets in an Ultra-Light Mid-Size Diesel Engine. SAE Int. J. Engines 2019, 12, 129-144. [CrossRef]

2. Di Blasio, G.; Ianniello, R.; Beatrice, C. Hydrotreated vegetable oil as enabler for high-efficient and ultra-low emission vehicles in the view of 2030 targets. Fuel 2022, 310, 122206. [CrossRef]

3. Ge, J.C.; Yoon, S.K.; Song, J.H. Comparative Evaluation on Combustion and Emission Characteristics of a Diesel Engine Fueled with Crude Palm Oil Blends. Appl. Sci. 2021, 11, 11502. [CrossRef]

4. Ge, J.C.; Kim, H.Y.; Yoon, S.K.; Choi, N.J. Optimization of palm oil biodiesel blends and engine operating parameters to improve performance and PM morphology in a common rail direct injection diesel engine. Fuel 2020, 260, 116326. [CrossRef]

5. Yasin, M.H.M.; Mamat, R.; Ali, O.M.; Yusop, A.F.; Hamidi, M.A.; Ismail, M.Y.; Rasul, M. Study of Diesel-biodiesel Fuel Properties and Wavelet Analysis on Cyclic Variations in a Diesel Engine. Energy Procedia 2017, 110, 498-503. [CrossRef]

6. Mohan, B.; Yang, W.; Chou, S.K. Fuel injection strategies for performance improvement and emissions reduction in compression ignition engines-A review. Renew. Sustain. Energy Rev. 2013, 28, 664-676. [CrossRef]

7. Luckhchoura, V.; Peters, N.; Diwakar, R. Computational analysis of injection-rate shapes in a small-bore direct-injection diesel engine. Int. J. Engine Res. 2011, 12, 145-168. [CrossRef]

8. Zhang, L.; Su, T.; Feng, Y.; Ma, F.; Zhang, Y.; Wang, J. Numerical Investigation of the Effects of Rate-Shaped Main Injection on Combustion and Emission in an OPOC Two-Stoke Diesel Engine. J. Beijing Inst. Technol. 2019, 28, 226-233. [CrossRef]

9. D'Ambrosio, S.; Ferrari, A.; Mancarella, A.; Mittica, A. Effects of Rate-Shaped and Multiple Injection Strategies on Pollutant Emissions, Combustion Noise and Fuel Consumption in a Low Compression Ratio Diesel Engine. Int. J. Automot. Technol. 2020, 21, 197-214. [CrossRef]

10. Atzler, F.; Kastner, O.; Rotondi, R.; Weigand, A. Multiple injection and rate shaping Part 1: Emissions reduction in passenger car Diesel engines. In Proceedings of the 9th International Conference on Engines and Vehicles, Capri, Italy, 14-17 September 2009. [CrossRef]

11. Macián, V.; Payri, R.; Ruiz, S.; Bardi, M.; Plazas, A.H. Experimental study of the relationship between injection rate shape and Diesel ignition using a novel piezo-actuated direct-acting injector. Appl. Energy 2014, 118, 100-113. [CrossRef]

12. Juneja, H.; Ra, Y.; Reitz, R.D. Optimization of Injection Rate Shape Using Active Control of Fuel Injection. In Proceedings of the SAE 2004 World Congress \& Exhibition, Detroit, MI, USA, 8-11 March 2004. [CrossRef]

13. Desantes, J.M.; Benajes, J.; Molina, S.; González, C.A. The modification of the fuel injection rate in heavy-duty diesel engines. Part 1: Effects on engine performance and emissions. Appl. Therm. Eng. 2004, 24, 2701-2714. [CrossRef] 
14. DeSantes, J.M.; Benajes, J.; Molina, S.; Gonzalez, C.A. The modification of the fuel injection rate in heavy-duty diesel engines: Part 2: Effects on combustion. Appl. Therm. Eng. 2004, 24, 2715-2726. [CrossRef]

15. Shrestha, A.; Zheng, Z.; Badawy, T.; Henein, N.A. Computational analysis of a diesel engine autoignition, combustion, and emissions using injection rate shapes. In Proceedings of the ASME 2013 Internal Combustion Engine Division Fall Technical Conference, Dearborn, MI, USA, 13-16 October 2013. [CrossRef]

16. Hountalas, D.T.; Kouremenos, D.A.; Pariotis, E.G.; Schwarz, V.; Binder, K.B. Using a Phenomenological Multi-Zone Model to Investigate the Effect of Injection Rate Shaping on Performance and Pollutants of a DI Heavy Duty Diesel Engine. In Proceedings of the SAE 2002 World Congress \& Exhibition, Detroit, MI, USA, 4-7 March 2002. [CrossRef]

17. Shuai, S.; Abani, N.; Yoshikawa, T.; Reitz, R.D.; Park, S.W. Evaluation of the effects of injection timing and rate-shape on diesel low temperature combustion using advanced CFD modeling. Fuel 2009, 88, 1235-1244. [CrossRef]

18. Tay, K.L.; Yang, W.; Zhao, F.; Yu, W.; Mohan, B. Effects of triangular and ramp injection rate-shapes on the performance and emissions of a kerosene-diesel fueled direct injection compression ignition engine: A numerical study. Appl. Therm. Eng. 2017, 110, 1401-1410. [CrossRef]

19. Tay, K.L.; Yang, W.; Zhao, F.; Yu, W.; Mohan, B. Numerical investigation on the combined effects of varying piston bowl geometries and ramp injection rate-shapes on the combustion characteristics of a kerosene-diesel fueled direct injection compression ignition engine. Energy Convers. Manag. 2017, 136, 1-10. [CrossRef]

20. Tay, K.L.; Yang, W.; Zhao, F.; Yu, W.; Mohan, B. A numerical study on the effects of boot injection rate-shapes on the combustion and emissions of a kerosene-diesel fueled direct injection compression ignition engine. Fuel 2017, 203, 430-444. [CrossRef]

21. He, Z.; Xuan, T.; Xue, Y.; Wang, Q.; Zhang, L. A numerical study of the effects of injection rate shape on combustion and emission of diesel engines. Therm. Sci. 2014, 18, 67-78. [CrossRef]

22. Bai, F.; Zhang, Z.; Du, Y.; Zhang, F.; Peng, Z. Effects of Injection Rate Profile on Combustion Process and Emissions in a Diesel Engine. J. Combust. 2017, 2017, 9702625. [CrossRef]

23. Mohan, B.; Yang, W.; Yu, W.; Tay, K.L.; Chou, S.K. Numerical investigation on the effects of injection rate shaping on combustion and emission characteristics of biodiesel fueled CI engine. Appl. Energy 2015, 160, 737-745. [CrossRef]

24. Miron, L.; Racovitza, A.; Chiriac, R. On the possibilities to reduce compression ignition engine emissions by controlling the reactivity of diesel-biofuel mixtures. IOP Conf. Ser. Earth Environ. Sci. 2020, 463, 012017. [CrossRef]

25. AVL-BOOST Theory 2019. Available online: https://www.avl.com/- /avl-boost- (accessed on 28 November 2021). 